\title{
Akademi Sepakbola Usia Dini dengan Pendekatan Arsitektur Perilaku
}

\author{
Junus M. A. Kbarek dan Nur Endah Nuffida \\ Departemen Arsitektur, Fakultas Teknik Sipil dan Perencanaan, Institut Teknologi Sepuluh Nopember (ITS) \\ e-mail:nuffida@gmail.com
}

\begin{abstract}
Abstrak-Permasalahan Sepakbola di Indonesia sudah cukup mengkhawatirkan, Regenerasi pemain sepakbola Indonesia sulit terjadi akibat pemain muda yang kurang mempunyai skill, bakat dan teknik yang mumpuni, sehingga terjadi stagnansi. Fasilitas pendidikan sepakbola yang ada di Indonesia sangat minim, sehingga sepakbola Indonesia sulit untuk bersaing dan berprestasi. Tujuan dari proyek ini adalah untuk meningkatkan skill, teknik dan teori sepakbola pemain Indonesia, dari usia dini. Karena sangat fundamental terhadap perkembangan pemain sepakbola Indonesia. Institusi pendidikan yang fokus pada perkembangan anak usia dini usia 5 - 12 Tahun. Yang merupakan gabungan antara sepakbola dan sekolah formal sehingga pendidikan anak tidak tertinggal.
\end{abstract}

Kata Kunci-Sepakbola, Akademi, Sekolah, Anak, Perilaku, Regenerasi.

\section{PENDAHULUAN}

$\mathrm{P}$ ERJALANAN sepakbola Indonesia tercatat dalam sejarah pertama kali tampil dan tercatat mulai sejak 5 Juni 1938 memulai debut melawan Hungaria, walau masih menggunakan nama Hindia Belanda. (Wikipedia, 2015).

Kiprah yang bersejarah bagi sepakbola Indonesia, ialah saat meraih prestasi gemilang pertama ketika Indonesia secara mengejutkan mampu lolos ke ajang Piala Asia untuk pertama kalinya. Bermain di Arab Saudi sebagai tuan rumah, pasukan Danurwindo tersebut bahkan sukses menahan imbang tim kuat, Kuwait, dengan skor 2-2. Kemudian sea games 1997 indonesia dengan semangat yang membara mampu melaju ke final dengan gagah,walau memang harus memang mengakui keunggulan Thailand di final.

Namun patut disayangkan olahraga rakyat ini sudah sangat jauh dari prestasi,untuk sekedar prestasi tim nasional (TIMNAS) di kancah persepakbolaan tingkat Asia Tenggara saja Indonesia belum pernah meraih juara, prestasi terbaik di piala AFF hanya menjadi runner-up pada tahun 2000, 2002, 2004, 2010 dan 2016 (dan menjadikan Indonesia negara terbanyak peraih runner-up dari seluruh negara peserta Piala AFF). Di ajang SEA Games pun Indonesia jarang meraih medali emas, yang terakhir diraih tahun 1991. (Wikipedia, 2016)

Peringkat Indonesia di FIFA semakin menurun, dalam sejarahnya, Indonesia pernah menembus peringkat 87 daftar peringat FIFA pada 1998 dan 2001. Sejak 2001 itulah peringkat Indonesia terus menurun. Pada 2004, Indonesia terakhir menghuni 100 besar dengan peringkat 91. Setelah itu, Indonesia selalu berada di bawah peringkat 100 dunia. (Tempo, 2015)

Satu masalah yang juga hadir yaitu akibat kurang-nya regenerasi di tim nasional karena, pemain asli Indonesia sendiri sulit bersaing dengan pemain asing yang di datangkan ke Indonesia. Pembinaan usia muda di mulai baru saat mereka remaja, usia yang baik untuk mulai mengenal sepakbola ialah di usia 5 - 12 Tahun di saat bakat-bakat ini masih berusia dini, (Timo Sheunemann, 2012) Sedangkan di Indonesia sendiri kebanyakan fokus di saat pemain berusia belasan yang artinya sudah terlambat untuk perkembangan kemampuan sepakbolanya.

Fasiitas yang ingin dibuat adalah sebuah institusi pendidikan untuk anak usia 5 -12 tahun, berupa sekolah dasar (SD). Dengan Sekolah Sepakbola, keduanya tersingkron sehingga seperti sekolah kejuruan.

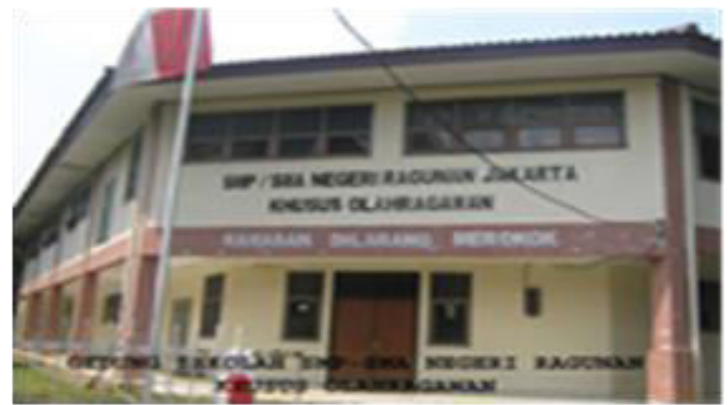

Gambar 1. Contoh Sekolah Kejuruan Olahraga.

\section{METODE PERANCANGAN}

Menurut Kari Jormakka dalam Basics Design Methods, terdapat beberapa klasifikasi metoda desain, metoda yang dipilih dalam proses perancangan ini adalah Rationalist Approaches. Dalam pendekatan rasional, arsitektur membutuhkan adanya pengetahuan dasar di berbagai bidang di luar arsitektur. Dasar yang rasional dan informasi spesifik (misalnya mengenai lahan, program) tersebut digunakan dalam perancangan. Terdapat parameter - parameter untuk mengevaluasi alternatif yang ada.

Permasalahan arsitektur pada objek rancang ini berkaitan dengan isu anak usia dini Dalam merancang diperlukan pertimbangan khusus mengenai dimensi,warna,organisasi ruang terhadap sisi psikologis anak. Ketika masih berusia belia anak tidak bisa dipaksa dalam melakukan sesuatu. Cara paling efektif dalam mengajari anak ialah dengan bermain sambil belajar.

\section{A. Anak Usia Dini}

Lickona (dalam Woolfolk, 2006) mengatakan bahwa variasi dalam situasi akan menghasilkan variasi dalam perilaku. Suasana yang dibangun dalam satu situasi yang mendekati kehidupan yang sebenarnya, dapat menyebabkan anak menjadi kaya akan pengalaman. Anak tidak saja berpikir dan bertindak dari sisi kognitifnya saja, namun juga menggunakan atau mengasah ranah non kognitifnya. 
Dengan demikian mereka dapat berkembang secara optimal menjadi manusia seutuhnya (secara horisontal dan vertikal).

Anak belajar melalui berbagai cara antara lain melalui imitasi, melakukan sesuatu atau mencoba dan mengalami (Einon, 2005). Lingkungan menyediakan sesuatu yang dibutuhkan anak, dan anak akan memanfaatkan apa yang ditawarkan oleh lingkungan. Orang dewasa dapat melatih, menjelaskan, dan mengoreksi anak, atau menunjukkan sesuatu kepada anak. Oleh karena itu yang dapat dila- kukan adalah membantu anak untuk melibatkan dan mendorong anak untuk mencoba dan mengalami. Anak mempu- nyai bakat atau kemampuan yang telah dibawa sejak lahir, namun bakat atau kemampuan tersebut tidak akan berkembang apabila tidak memperoleh rangsangan dari lingkungannya

Pendidikan anak usia dini merupakan suatu bentuk stimulasi yang pada dasarnya adalah upaya-upaya intervensi yaitu menciptakan lingkungan sekitar anak usia dini agar mampu menstimulasi seluruh aspek perkembangan anak. Intervensi merupakan sejumlah informasi yang diatur melalui pembelajaran tertentu untuk pertumbuhan, perkembangan maupun perubahan perilaku

Melalui objek Arsitektur berupa Akademi Sepakbola ini yang menjadi acuan adalah perilaku anak, juga psikologinya, ketika seorang anak masuk ke akademi untuk mengejar impiannya, ia akan masuk ke situasi baru yang bisa membuatnya nervous dan grogi untuk itu seperti yang dijelaskan Lickona bahwa akademi ini perlu dibuat atau direkayasa memiliki kesan yang sangat kekeluargaan sehingga anak yang masuk disini bisa nyaman imbasnya ia akan bisa menikmati hari-harinya disini dengan demikian hasil yang baik bisa tercapai.

\section{B. Akademi Sepakbola}

Akademi sepakbola merupakan sebuah institusi pendidikan yang menerapkan konsep kepelatihan yang mencoba mengembangkan pemain sepakbola sejak usia dini, ditanamkan nilai-nilai sepakbola,disiplin serta menanamkan karakter yang mencerminkan seorang olahragawan sejati yang menjunjung nilai-nilai sportivitas. Akademi sepakbola sudah sepaket dengan pendidikan formal, di inggris contohnya mereka sekolah dipagi hari lalu beristirahat kemudian berlatih sepakbola disore hari hingga malam. Ritme yang terus dipertahankan membuat setiap pemain sudah merasakan denyut dari sepakbola itu sendiri. Denyut berupa kompetisi, yang membangun,serta memberikan persaingan yang ketat sehingga setiap pemain merasa mereka harus terus berlatih agar bisa meraih hasil yang maksimal. Ini nilai-nilai yang ingin ditanamkan didalam setiap pemain didikan Akademi ini.

Dengan metode pendekatan rasional, didapatkan data mengenai karakteristik dan kebutuhan pengguna, khususnya sepakbola untuk anak yang berusia dini yang menjadi acuan utama. Informasi tersebut diolah menjadi respond dan konsep yang spesifik.

\section{Arsitektur dan Perilaku Manusia}

Lingkungan fisik mempengaruhi psikologi, perilaku, serta pengalaman manusia. Bukan hanya aspek fisik seperti cahaya, bunyi, bentuk, dan warna yang mempengaruhi psikologi manusia. Aspek lain seperti organisasi ruang dan pemaknaan, skala, dan hal yang lebih spesifik lainnya dapat mempengaruhi psikologi penggunanya. Arsitektur dapat mempengaruhi perilaku penggunannya dengan empat cara
(Calhoun, 1995) yaitu menghalangi perilaku, mengundang perilaku, membentuk kepribadian, serta mempengaruhi citra diri. Ruang lingkup dalam arsitektur dan perilaku mencakup tiga hal (Moore dalam Snyder \& Catanese,1994) Pertama adalah fenomena lingkungan-perilaku, contohnya proxemics. Proxemic adalah jarak tertentu yang dianggap manusia nyaman untuk melakukan interaksi social. Jarak tersebut berbeda-beda pada tiap individu. Fenomena-fenomena seperti ini perlu dipertimbangkan dalam proses perancangan disesuaikan dengan kelompok pengguna. Dengan metode pendekatan rasional, didapatkan data mengenai karakteristik dan kebutuhan pengguna, khususnya anak usia dini (U9U12). Informasi tersebut diolah menjadi respond an konsep yang spesifik.

\section{PENERAPAN KONSEP}

Akademi Sepakbola merupakan suatu institusi pendidikan berbasis sepakbola, sama dengan halnya Akademi Militer yang juga merupakan Institusi pendidikan berbasis kemiliteran, keduanya mempunyai tujuan yang sama yakni menciptakan seorang yang tahu makna dibalik kemiliteran maupun sepakbola di akademi diajarkan kemampuan yang mendasar hingga yang advance. Untuk di akademi sepakbola diajarkan tentang dua hal yakni Hardskill berupa cara mengolah bola, kemudian teknik-teknik sepakbola yang mendasar. Diharapkan dari hal yang mendasar inilah para peserta didik mampu untuk mengembangkan dirinya didalam sepakbola. Berbeda dengan yang bukan lulusan akademi ia cenderung melakukan semua sendiri namun pemain dengan didikan akademi mampu untuk lebih teratur, disiplin serta paham tentang filosofi dan makna dibalik cara bermain sepakbola yang dianut negaranya atau klubnya. Sehingga membuat lulusan akademi seperti mempunyai kelas tersendiri dari pemain yang hanya sekedar bakat, karena di akademi sudah menggunakan sports science untuk memaksimalkan kemampuan setiap pemain agar bisa tampil maksimal, semisal dengan lebih banyak berlatih di gym sehingga ototnya bisa lebih besar dan mampu bertarung di lapangan dengan lebih kuat.

Akademi Sepakbola ini menggunakan pendekatan secara Behaviour dengan berfokus pada pengguna objek arsitektural ini. Dengan konsep behavior atau perilaku manusia dengan rancangan bisa dengan mendesain suatu desain yang menghalangi perilaku, jika pemain di beri suatu kamar sendiri ia akan lebih mudah atau cenderung menjadi penyendiri dan merasa tidak membutuhkan orang lain, jika ingin suatu kebersamaan maka desainlah suatu kamar yang bisa terdiri dari beberapa anak maupun juga bisa dengan cara tanpa kamar namun berupa barak yang seperti cara militer yang dibuat tempat tidur tanpa pembatas. Juga selain menghalangi perilaku ketika menginginkan suatu perilaku bisa tercipta maka bisa dengan cara "Mengundang Perilaku" Melalui desain, semisal ketika mendesain ruang belajar untuk menambah fokus belajar bisa dengan menggunakan material yang nyaman dan juga menggunakan warna cat yang berwarna sehingga mengundang keinginan belajar. 


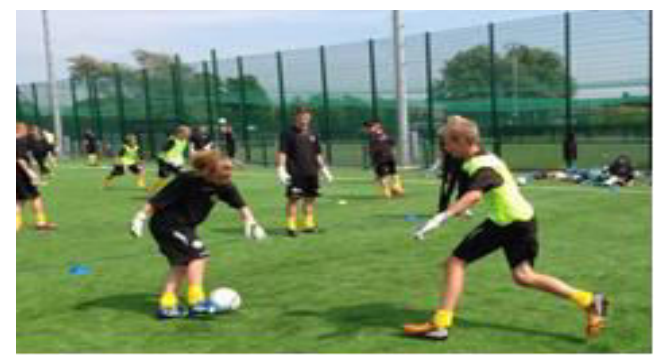

Gambar 2. Akademi Sepakbola.

\section{A. Konsep Bentuk}

1. Eksplorasi desain 1

Eksplorasi awal dilakukan berkaitan dengan lahan dan zoning. Lahan berbatasan langsung dengan dua jalan, jalan jawar dan jalan stadion bung tomo.

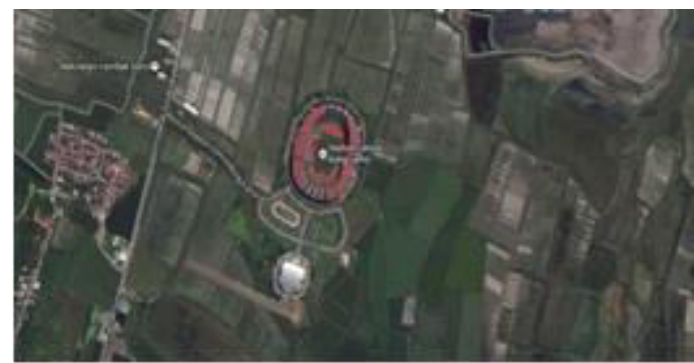

Gambar 3. Map Site

Jalur yang digunakan hanya di jalan jawar, karena merupakan jalan umum, jalan stadion bung tomo sering ditutup saat tidak ada pertandingan sepakbola, dengan alasan tersebut maka jalur keluar masuk pada site akan ditempatkan pada jalan jawar.

\section{Eksplorasi desain 2}

Alur sirkulasi yang hadir kemudian dibuat agar fleksibel, mengalir dan efektif.

Bentuk Shape sendiri di ambil dari penelitian Cristopher Day tentang anak yang menggambarkan jika anak itu menyukai sesuatu yang mengalir dan tidak monoton. Shape memberi kesan fleksibel dan lugas, tidak linier, dan tidak membosankan.

\section{B. Konsep Full Colour}

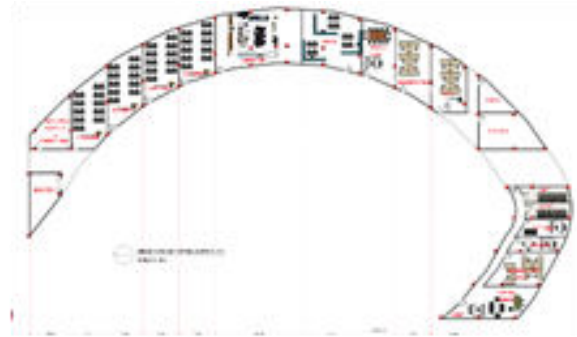

Gambar 4. denah sekolah formal.

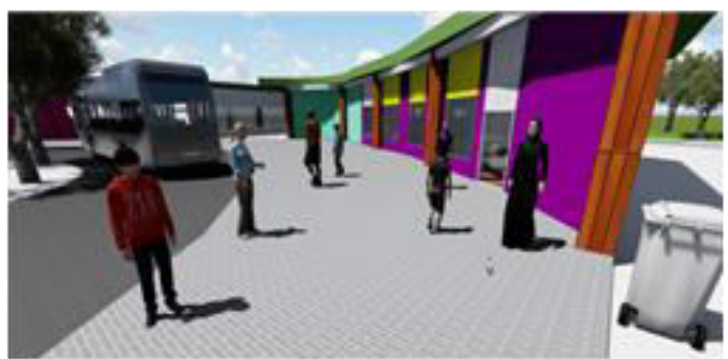

Gambar 5. Perspektif.

Karena fungsinya sebagai sekolah dasar maka, desain dibuat agar menencourage anak untuk belajar, dengan banyak warna, menambah kesan ceria, agar anak tidak tertekan saat berada dilingkungan sekolah.

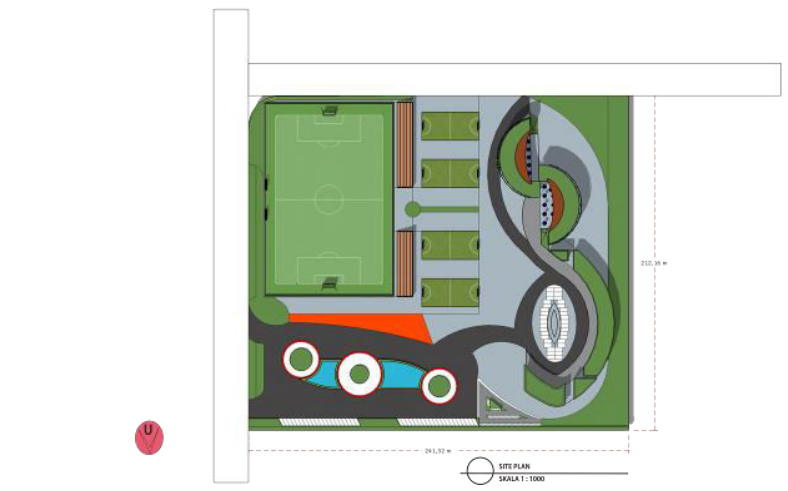

Gambar 6. Site Plan.

\section{Konsep Sociofugal dan Sociopetal}

Konsep sociofugal bertujuan agar menghalangi perilaku, ditujukan untuk tempat yang membutuhkan konsentrasi tinggi, seperti di ruang kelas dan di perpustakaan. Dengan demikian anak perlahan-lahan akan mengetahui dimana ia bisa bermain bebas dan dimana tempat yang memerlukan konsentrasi lebih.

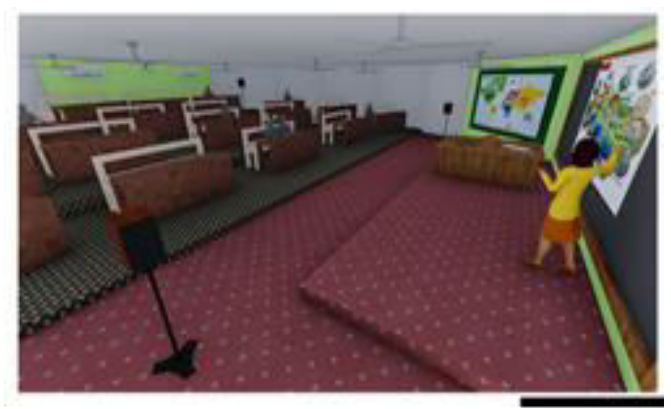

Gambar 7. Ruang Kelas

Konsep Sociopetal bertujuan untuk menencourage anak untuk berinteraksi lebih, misalnya di meja makan, di taman bermain.

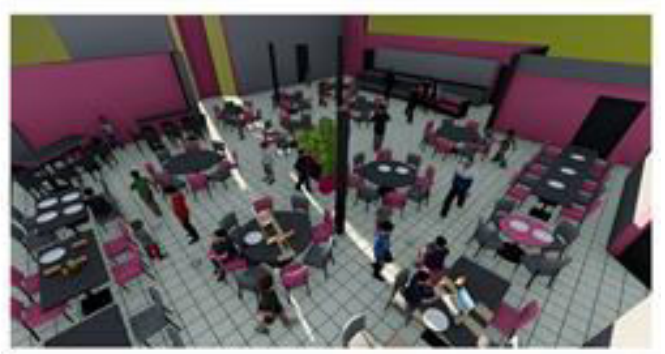

Gambar 8. Cafetaria. 


\section{KESIMPULAN}

Akademi Usia Dini di rancang berdasarkan isu mengenai regenerasi pada sepakbola di Indonesia, gap yang ditinggalkan membuat prestasi sepakbola Indonesia menjadi tidak menentu, di harapkan dengan desain ini, yang berfungsi sebagai Akademi Sepakbola Usia Dini ini mampu memberi sumbangsi bagi kemajuan sepakbola indonesia, memang perlu waktu agar pemain-pemain yang di didik tumbuh dewasa,namun begitulah proses yang harus di lalui ketika menginginkan sebuah prestasi, karena tidak ada yang datang dengan murah dan cepat. Perlu rencana jangka panjang agar keinginan dapat terwujud. Akademi Sepakbola ini bisa menjadi batu loncatan pemain berusia $9-12$ Tahun menuju jenjang selanjutnya, Usia ini merupakan tahap fondasi sehingga sangat penting bagi perkembangan pemain, ketika fondasinya sudah cukup kuat, membangun tembok dan atapnya hanya perlu waktu.

\section{DAFTAR PUSTAKA}

[1] White, Edward $T$, Site Analysis Diagramming Information for Architectural Design. Architectural Media: Florida. 2004

[2] Scheunemann, S Timo, Kurikulum \& Pedoman Dasar Sepak bola Indonesia, PSSI, Jakarta. 2012.

[3] Laurens, Marcella Joyce, Arsitektur Perilaku Manusia, Irasindo, Surabaya. 2004.

[4] Day, Christopher, Environment and Children, Architectural Press. 2007. 